\title{
Transforming the Architectural Curriculum, Integrated Practice and the Metrics of Performance
}

\section{IDENTIFYING THE QUESTION}

The research question at the center of this paper was initiated in response to my participation in a larger Department of Energy funded project awarded to the Greater Philadelphia Innovation Cluster for Energy Efficient Buildings (GPIC). My particular research initiatives within GPIC are focused on developing a roadmap of use by architects, engineers, builders and building owners for the successful implementation and market adoption of rigorous Integrated Design Practices in the energy efficient retrofit of buildings in a 10 county region of the Mid Atlantic region, that includes the city of Philadelphia and its Navy Yard. A group of computer scientists and building engineers comprise the Integrated Technologies Team, whose "subtask [is to] utilize models, tools, and methods developed by the Design Tools Team for rapid synthesis of systems." ${ }^{1}$ And a sub-group of researchers from the Architecture Department at the University of Pennsylvania is more broadly devising innovative Integrated Design strategies that can be implemented in the process of whole building design of high performance buildings.

\section{INTEGRATED PRACTICE AND THE ARCHITECTURAL CURRICULUM}

Integrated Design and its various project delivery methods are actively promoted by many sectors of the building industry as the emergent paradigm poised to transform the very way in which buildings, landscapes and urban environments are built. Hyperbole or not, this field and its set of associated practices continues to expand and its supporters grow in numbers. In the next decade, changes brought about by Integrated Project Delivery Methods will have a profound effect on the way in which architects practice, structure their relationships to others in the construction industry, and conceive of the very process of design. This altered context for the construction of our built environment will be the professional climate in which our graduates will be practicing.

The question posed in this paper is whether accredited schools of architecture have begun to address the implications this will have on the teaching of design, theory, construction, structures, environmental systems and professional practice? To what extent are significant curricular transformations required in the face 
of such changes? Is a possible to articulate a methodologically precise and polemically neutral curriculum for accomplishing the required transformations to architectural education? Can educators identify a common ground upon which the development of a shared intellectual structure could be posited for conceptualizing, articulating, measuring and critically evaluating significant modifications to an existing pedagogical structure, which at its core, is more than half a century old?

Many have been the conversations amongst architects and educators, to try and establish a path to this end, including the 2006 ACSA Oak Park Conference and the 2007 ACSA Cranbrook Teacher's Seminar that discussed this very issue. The resulting publication from the latter event, called Integrated Practice and the Twenty First Century Curriculum continues to be of value in the way in which it addresses the following question. What are the possible, probable and desirable curricular changes that must be brought to bear on the education of the architect whose profession is increasingly committed to Integrated Project Delivery, BIM and the actualization of knowledge made possible by performance based tools? The publication recorded both presentations and workshops that sought to answer this question all the while it foregrounded ethical issues and questions of responsibility, the influence of professional practice, as well as the role to be played by research and design. It continues to offer its readers important provocations, strategies and initiatives for addressing the issues at hand.

In addition, initiatives have been undertaken at various schools of architecture to focus significant parts of their curriculum on addressing this need for integration. In some instances new professional and post professional graduate programs have been instituted dedicated to Integrative Design and its allied fields of $\mathrm{BIM}$, performance based design and environmental design. This is the case at the College of Architecture, Design and Construction at Auburn University whose Integrated Project
Delivery Program (a joint architecture / building construction program) gathers the expertise of construction management to bear on architectural design. Academic networks have also been created with the goal of promoting Integration such as the Integrated Design Lab Network which is a consortium of six universities in the Pacific Northwest including; the Energy Studies in Buildings Laboratory at the University of Oregon at Eugene + and Portland, the Integrated Design Lab at the University of Idaho in Boise [IDL], the Integrated Design Lab at Montana State University in Bozeman, and the two Integrated Design Labs of the University of Washington's College of Built Environments, Department of Architecture, located in Seattle and Spokane respectively. The Integrated Technology in Architecture Center at the University of Utah is yet another example of initiatives arising from within schools of architecture. Its director Ryan Smith identifies as part of its goals, "efficient performance oriented design and construction." ${ }^{2}$ And from the group of schools that have instituted advanced programs in performance based design environmental design, the University of Pennsylvania has launched its post professional Master of Environmental Building Design program that is heavily focused on the role of performance simulation and integrated practices in architectural design.

\section{THE AIA AND INTEGRATED PROJECT DELIVERY}

The American Institute of Architects (AIA) is unconditionally committed to the promotion and development of Integrated Design Practices as evidenced by the significant research they've produced and made available to their constituency promoting its value. Theirs have been the most comprehensive initiatives undertaken to date that evaluate the possible opportunities and outcomes this industry wide change may have on the profession as a whole. They've published a wide range of resources for architects and educators alike interested in cultivating the larger intellectual context within which 
changes to the profession can be articulated, organized and effected.

In this regard they established the AIA Center for Integrated Practice; an online resource dedicated to empowering the architect in his /her role as manager of the design and construction process. The Center "leverages resources related to project delivery, technology, architectural practice, and stakeholder relationships; removes barriers to collaboration, serves as a collector and conductor of project delivery outcomes and research, and develops resources and tools for members, the profession, and the public." 3

The AIA also developed an 'Integrated Project Delivery' (IPD) method that is a legal vehicle for defining the contractual relationships that bind all parties involved in the process. Contrary to the traditional Design/ Bid/ Build Contract, the idealized IPD method involves an entirely new contractual relationship between participants (designers, engineers, owners and builders) such that all participants; assume responsibility for setting the project's goals, assume responsibility for identifying the best means and methods for executing the project, assume risk and liability for the project's outcomes, and are responsible for apportioning rewards and profits. The C191-2009, Standard Form MultiParty Agreement for Integrated Project Delivery states that it is a;

"standard form multi-party agreement through which the owner, architect, contractor, and perhaps other key project participants execute a single agreement for the design, construction and commissioning of a Project. AlA Document C191-2008 provides the framework for a collaborative environment in which the parties operate in furtherance of cost and performance goals that the parties jointly establish. This collaborative process has the potential to result in a high quality project for the owner, and substantial monetary and intangible rewards for the other parties." ${ }^{4}$
In 2007, the AlA published a 62 page Guide called Integrated Project Delivery: A Guide, which defined the practice as a "method of project delivery distinguished by a contractual arrangement among a minimum of owner, constructor and design professional that aligns business interests of all parties." ${ }^{5}$ And the Guide identified both contractual and behavioral principles essential to the process. The seven contractual principles included; Key Participants Bound Together as Equal, Shared Financial Risk and Reward Based on Project Outcome, Liability Waivers between Key Participants, Fiscal Transparency between Key Participants, Early Involvement of Key Participants, Jointly Developed Project Target Criteria and Collaborative Decision Making. The three behavioral principles included; Mutual Respect and Trust, Willingness to Collaborate, and Open Communication.

In 2006, the AIA had also published a set of "Reports on Integrated Practice", subsequently revised in 2009 by the Integrated Practice Discussion Group (IPDiG). The results of this later initiative are available on-line and include an anthology of personal statements from practitioners and educators committed to the practice. Those who've contributed reflections on the subject include practitioner Thom Mayne, educators Renee Cheng and Chuck Eastman and engineer Joseph Burns. ${ }^{6}$ The reports review special topics such as BIM and international developments that are important to Integrated Project Delivery. And the report treating architectural curricula reform, Suggestions for an Integrative Education, was authored by Renee Cheng and identifies the significant influence exerted by BIM on the process of pedagogical reform.

In 2010, the AIA sponsored academic research in the form of Case Studies. The "Integrated Project Delivery Case Studies (2010)" project was co-sponsored by the AIA California Council - Integrated Project Delivery Steering Committee and the AIA National Integrated Practice Discussion Group. Jonathan Cohen (FAIA) au- 
thored the report that analyzed 6 building projects constructed using IPD methods; including the Walter Cronkite School of Journalism at Arizona State and the Autodesk AEC Headquarters in Massachusetts. This early study demonstrated how the chosen projects engaged 6 of the original 10 principles established in the 2007 Guide, and listed above; Early Involvement of Key Participants, Shared Risk and Reward, Multi-Party Contract, Collaborative Decision Making and Control, Liability Waivers Among Key Participants, and Jointly Developed and Validated Project Goals.

In 2011 another set of Case Studies were published. ${ }^{7}$ This time, Renee Cheng and Katy Dale from the School of Architecture at the University of Minnesota coauthored the "Integrated Projective Delivery Case Studies (2011)" which analyzed 5 additional buildings that employed IPD methods in their construction. Programmatically, the buildings ranged from hospitals to offices and their sizes varied from 7000sq. $\mathrm{ft}$ to over 800,000 sq.ft. These case studies assessed more carefully how the various projects incorporated a more ample list of strategies including Legal and Commercial Strategies, Management Strategies, Social Strategies, and Environmental and Technological Strategies. ${ }^{8}$

\section{CRITIQUE OF THE AIA IPD METHOD}

Surely the 2010 and 2011 Case Study projects were successful in bringing to the attention of AIA members eleven fairly different architectural projects that benefited from the use of IPD methods. In the 2011 publication the case studies were detailed offering the reader substantial and useful information. However, all of the case studies were primarily focused on discussing information particular to the management of the building process and its contract with a fairly detailed review of how the various parties collaborated throughout the life of the contract and the project's construction. This is surely important in trying to identify a range of best practices. However, in what concerns learning about the implications the method has for the practice of architecture, in trying to identify what the process affords architectural design, and in trying to establish lessons for architectural education reform, there is little that bridges the conceptual gap between the architect as contract manager and the architect as designer.

Instead, what is needed is a demonstration of how Integrated Design has benefits for architectural design and how it contributes to establishing new value for the work of architecture. As such, a greater portion of these case studies could have, and should have been dedicated to identifying how it is that IPD best facilities the introduction of added design value. Can IPD methods result in better works of architecture or merely better processes for the management of construction? In fact, can IPD methods result in better performing works of architecture?

\section{DEFINITION OF INTEGRATED PRACTICE}

Possibly, the answer to this series of questions resides in the complexity that surrounds the very definition of Integrated Practice. In this paper, I have used a number of different words to describe a set of practices generally aligned with the idea of Integration. This is, in fact, because a number of different methodologies and conceptual frameworks participate in its definition. As such, I would assert what is meant by Integrated Practice is contingent upon the particular subfield within which its activities take place.

The figure of the diagram here included was designed to describe five subfields in the design and construction industry wherein various modes of Integration are engaged. These include the subfields of Data Management (Integrated Tools), Engineering (Integrated Building Systems), Architecture (Integrated Design), Construction (Integrated Project Delivery) and lastly, Policy (Integrated Policy, Behavioral, Financing + Markets). From the left to the right of the diagram, the scope and character of 
what is integrated transforms from the realm of simulation tools and monitors, to building systems and their technologies, to the scale of the building as a whole, to the construction process used in bringing the building into being and to the set of human based operations that are conditioned by the way in which buildings are built. Each of these fields will subtend a slightly different interpretation of what is meant by Integrated Design and it is important for designers to become familiar with the language, limits and possibilities of each.

If seeking to understand the context of Integrated Design within architectural engineering and building systems design, Leonard Bachman's Integrated Buildings - The Systems Basis of Architecture is a productive resource. Integration must occur amongst a building's varied mechanical, electrical, plumbing and structural systems. The building's envelope, its MEP building services, and its structure are all considered systems requiring coordination and integration.
From the point of view of building construction and its management, and as noted in George Elvin's Integrated Practice in Architecture Mastering Design Build, Fast Track and Building Information Modeling, integration also must take place within the collaborative practices and exchanges that are integral to the execution of the construction contract. In this regard;

"Integrated Design is a holistic approach to building in which all project stakeholders and participants work in highly collaborative relationships throughout the complete facility life cycle to achieve effective and efficient buildings. Integrated practice providers include architects, engineers, construction managers, and contractors working together, either as fully integrated firms or in multiform partnerships." 9

As noted by Marian Keeler and Bill Burke in Fundamentals of Integrated Design for Sustainable Building, when considering the definition of Integrated Design from the position of

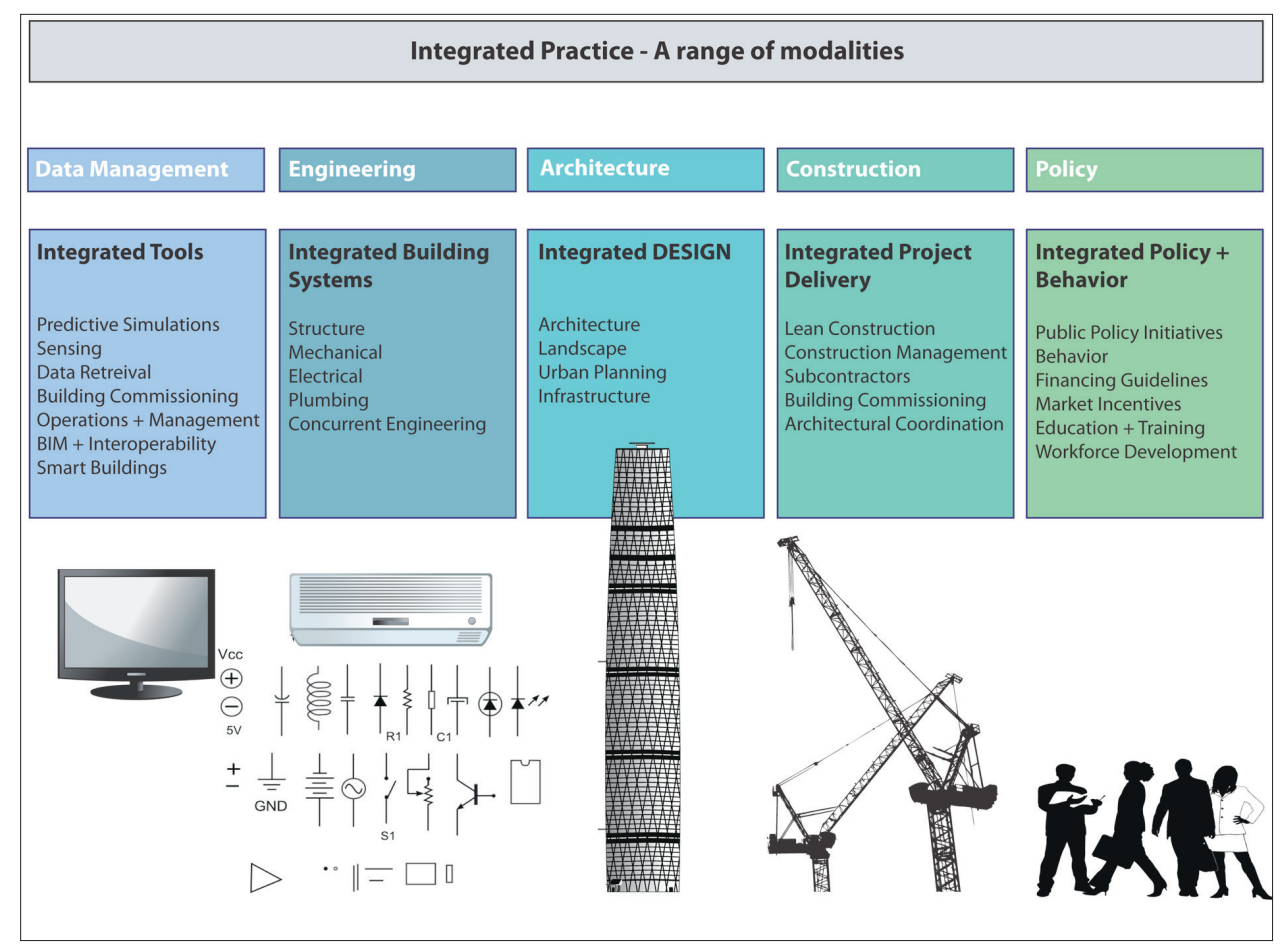


ecological design, its activities should be successfully framed by questions of sustainability such as the value of green building legislation, the chemical composition of the built environment, questions of indoor air quality, and issues of energy use and its accountability.

And lastly, when seeking a definition of Integration that valorizes the processes and practices more akin to architectural design, the work of Kiel Moe in Integrated Design in Contemporary Architecture, positions its practices at the very center of high performance building. The case studies featured in the book evidence the extent to which the merit of integrated practice for the design profession resides in its capacity to deliver a building which is more than a sum of its parts; a building, whose value with respect to high performance is measured, beyond its ability to integrate systems with data measuring technologies, and beyond its capacity to integrate design and construction methods. This is the tenet supported by this paper and promoted by a number of professionals in the building industry.

\section{WHOLE BUILDING DESIGN AND HIGH PERFORMANCE}

A select group of architects, structural, mechanical and electrical engineers have demonstrated their commitment to Integrated Design primarily by way of aligning its definition with that 'Whole Building Design'. The design and evaluation process for assessing the energy, material resources, carbon emission, life cycle and health costs associated with the design and construction of the built environment. Whole Building Design methods reject the highly segregated and dysfunctional nature of traditional building engineering that atomizes the building into its disparate parts. It articulates a new vision for the building; one that encompasses all of its physical and operational systems into a fully integrated whole. To this end, the Whole Building Design Guide produced by the National Institute of Building Sciences is dedicated to the delivery of " $a$ successful high-performance building by applying an integrated design and team approach to the project during the planning and programming phases." ${ }^{10}$ A building and its systems are conceived as wholly interdependent and their integration sought for improving their performance. ${ }^{11}$ In the United States, eleven governmental agencies participate in its goals, including the Department of Energy (DOE) and the General Services Administration (GSA); all of whom are committed to the Federal 'High Performance and Sustainable Building' (HPSB) Requirements made possible by the WBDG. As originally devised decades ago by architect and educator Don Prowler, the Guide facilitates the design of a High Performance Building by instituting:

"an integrated design approach and an integrated team process. The "integrated" design approach asks all the members of the building stakeholder community, and the technical planning, design, and construction team to look at the project objectives, and building materials, systems, and assemblies from many different perspectives." 12

The integrated design approach;

"is where project goals are identified early on and held in proper balance during the design process; and where their interrelationships and interdependencies with all building systems are understood, evaluated, appropriately applied, and coordinated concurrently." ${ }^{13}$

The integrated team process;

"is an interactive approach to the design process ... which includes a design charrette $-a$ focused and collaborative brainstorming session held at the beginning of a project-encourages an exchange of ideas and information and allows truly integrated design solutions to take form. Team members-all the stakeholders-are encouraged to cross fertilize and address problems beyond their field of expertise." ${ }^{14}$ The merit of Whole Building 
Design is that it "enable[s] you to think and practice in an integrated fashion to meet the demands of today's as well as tomorrow's high-performance building projects." ${ }^{15}$

Currently the field of High Performance Buildings is predicated on the establishment of metrics; measurements, evaluations and benchmarks. Quantitative assessments of a building and its systems are carried out using agreed to methods of analysis and results are measured against industry wide standards. ${ }^{16}$ Of most interest are the energy expended and materials consumed, during the construction and operation of a building. Non-renewable fossil fuels exhausted during a building's construction and operation, the embodied energy of materials contained therein, and more currently, carbon emissions resulting from construction, operations and decommissioning are all featured in these calculations. A number of significant institutional standards already exist for evaluating the performance of buildings, some of which have acquired the status of law while others significantly influence the culture of building albeit remain voluntary. The most prominent include LEED (Leadership in Energy and Environmental Design), BREEAM (BRE Environmental Assessment Method), and Green Globes, each highly participatory assessment mechanisms committed to knowledge building, information sharing and technology transfers that enable designers, builders and occupants to participate in the making of better performing environments.

Publications such as the Journal of Advanced and High Performance Materials and the Journal of Building Enclosure Design attest to the large number of professionals working in the field. The Journal High Performing Buildings is published by the American Society of Heating, Refrigerating and Air-Conditioning (ASHRAE) Engineers who in collaboration with the Illuminating Engineering Society of North America (IESNA), the Mechanical Contractors Association of America (MCAA), the U.S. Green Building Council (USGBC) and the Green Building
Initiative (GBI), has initiated the 'High Performance Building Design Professional Certification' program which trains building experts in the field of 'high performance' evaluation. ${ }^{17}$

One would be given to thinking, however, that with all this accumulated knowledge in the field of 'high performance' we would be in possession of a tried and true method for achieving its aims. Given the research, institution building and implementation strategies developed as early as the 1970s to achieve the goals of what was then referred to as 'energy conservation', why have we yet to agree on a definition of 'high performance' and on an Integrated Design method to achieve its goals? A possible answer lies in the writings of Richard Stein who in 1977, in the midst of the first 'energy' crisis to hit the United States, called his fellow architects to action. ${ }^{18}$ In Architecture and Energy, Conserving Energy Through Rational Design, Stein developed a comprehensive and convincing argument for recognizing that problems of energy conservation were, in fact, problems of design. After all, it was by design that office buildings were transformed into sealed artificial environments requiring tremendous inputs of air conditioning energy. It was by design that post war developments favored the growth of suburban sprawl. It was by design that tall buildings were conceived with building facades inarticulate as to their solar orientation. And it was by design, that the profession had relegated all knowledge of vernacular strategies for energy free architectural design to the dark recesses of history. Hence, it was only by design that radical change could be effected to our highly energy consumptive culture of building.

I would posit, therefore, that it is only by design that we can achieve High Performance Building through the various practices of Integrated Design. 
EDUCATING THE ARCHITECT AND

INTEGRATED PRACTICE

In an Interview given to AIA Architect by Thom Mayne of Morphosis for its series Integrated Practice / Project Delivery, Interview by Robert Smith, AIA, "2009 and Beyond | Revisiting the 2006 Report on Integrated Practice | "Change or Perish", Thom Mayne declared the following:

"Today I would think that you couldn't even run a practice without having advanced performance techniques for understanding the way your projects operate within functional terms, within environmental terms, within technological terms, and for looking at the development of a project in the early stages, the cost models that are connected to extremely precise performance objectives... Now we model not to describe a building but to manage relationships between trades... This notion of integration is quite simply a radical shift into increasing empowerment and our ability to control the reality of our own profession...I think we have to be harnessed immediately to a higher level design product and, by higher level, I mean a higher performance product." 19

The question remains, therefore, how do we perform the necessary changes to the architect's curriculum to address the issues raised by this leader in architectural design? How do we successfully incorporate performance metrics and techniques of integrated practice? And to what extent can the present studio culture contribute to the successful articulation of a robust definition of Integrated Practice? One not exclusively predicated on quantitative values of efficiency and cost, but one that incorporates an expanded definition of DESIGN that includes the following eight variables:

1. Rigorous adoption of analytical thinking and research methodologies such as those used in the sciences. Analysis is a word often used in architectural discourse; rarely, however, with methodological veracity and verifiability. Studio output could insist on evidence-based design and hypothesis based research.

2. Performance based design as a determining agent in form finding activities, such that the search for building expression is contingent upon its response to environmentally appropriate strategies; strategies that include, but are not exclusive to, smart energy and material use by the building and its occupants.

3. The valorization of construction technologies and building systems within the process of design such that the design process more quickly and effectively challenges the limitations inherent in architectural technology.

4. Appreciation of the value of high performance building metrics in the process of design, via the use of building simulation tools by introducing project deliverables that evaluate a building's lighting, thermal and air quality.

5. Adoption of the measure of Net Zero Energy as a design studio deliverable, encouraging the development of projects responsive to the verifiable metrics of net zero, carbon neutrality and life cycle assessment.

6. Incorporating the constraints of materiality in the studio environment as well as innovations made possible by material sciences. The use of material systems and emerging materials would be fundamental to the project's definition, as would the promotion of industry available products.

7. Introduction to the political and policy frameworks that govern the legislative aspect of construction by associating the studio within governmental and para-governmental agencies enabling students to 
confront the zoning, planning and political constraints which influence the process of design

8. Introduction of the role larger financial markets play in determining the credit basis for building.

The ability to engage the metrics of construction, energy usage, material forces, life cycle assessments, and credit ratings contributes to a better understanding of the very qualities associated with architectural design. However, each of these factors must transcend their technological definition to engage the design problem within socially and ethically appropriate contexts.

\section{CONCLUSION}

Integrated Practice is an emerging field of research and practice which implicates architects, engineers, construction consultants, builders, fabricators, construction managers, technologists, software engineers and policy makers in a process of shared responsibilities and mutual exchange. In so doing, it places many demands on the way in which architects engage their singular process of design; demands that must be addressed if their role is to be valorized in the quickly changing landscape of construction. But in so doing, it also affords the architect an incredible opportunity to share with others the richness and value which design can offer when its practices engage the larger demands of High Performance Design.

\section{ENDNOTES}

1. http://gpichub.org/activities/technologies/integrated-systems

2. http://itac.utah.edu/itac.utah.edu/HOME.html

3. http://network.aia.org/AIA/CenterforIntegratedPractice/Home/Default.aspx

4. http://www.aia.org/contractdocs/AIAS076747. The full list of AIA Contracts types can also be found ONline.

5. http://www.betterbricks.com/graphics/assets/documents/AIA-_IPD_Guide_2007

6. http://www.aia.org/about/initiatives/AIAB081793
7. http://www.aia.org/about/initiatives/AIAB087494

8. A more detailed description of the categories includes; Legal and Commercial Strategies - Contract, Goals, Risk/ Reward, Liability, Insurance; Management Strategies - Leadership, Firm Selection, Team Selection, Early Planning, Implementation; Social Strategies -- Early Involvement, Transparency, Decision Making, Culture; Environmental and Technological Strategies Workplace, Information Sharing, BIM

9. George Elvin's Integrated Practice in Architecture Mastering Design Build, Fast Track and Building Information Modeling, p. 19

10. http://www.wbdg.org

11. The ASHRAE publication, Sustainable Design and the High Performance BUILDING calls for the entire building to be conceived in the process of evaluating performance.

12. http://www.wbdg.org/wbdg_approach.php, Whole Building Design " by Don Prowler, FAIA - Donald Prowler \& Associates, Revised and updated by Stephanie Vierra - Steven Winter Associates, Inc., Last updated: 05-132011.

13. Ibid

14. Ibid.

15. Ibid.

16. So important is the concept of "High Performance" to the larger building industry that the very process by which a building is constructed is also being analyzed with the intent of formulating high performance metrics for the project's delivery. See Sinem Korkmaz, David Riley, and Michael Horman, "Piloting Evaluation Metrics for Sustainable High-Performance Building Project Delivery" in Journal of Construction Engineering and Management (August 2010): 877-884.

17. http://www.ashrae.org/certification/page/1683

18. Richard G. Stein, Architecture and Energy - Conserving Energy through Rational Design (Anchor Press/ Doubleday: New York, 1977).

19. Integrated Practice / Project Delivery, Interview by Robert Smith, AIA, "2009 and Beyond / Revisiting the 2006 Report on Integrated Practice / "Change or Perish". 